\title{
Preparation of Si(Al)ON Precursor Using Organoaluminum Imine and Poly (Phenyl Carbosilane), and the Compositional Change of the Film with Different Heat Treatment Condition
}

\author{
Yoonjoo Lee, Dong-Geun Shin, Woo Teck Kwon, Soo Ryong Kim, and Younghee Kim ${ }^{\dagger}$ \\ Energy Efficient Material Team, Korea Institute of Ceramic Engineering and Technology, Jinju 660-031, Korea
}

(Received June 22, 2015; Revised July 13, 2015; Accepted July 13, 2015)

\begin{abstract}
$\mathrm{Si}(\mathrm{Al}) \mathrm{ON}$ precursor was synthesized by formation of new Si-N bond using organoaluminum imine and liquid type poly(phenyl carbosilane). It was decomposed between $200-600^{\circ} \mathrm{C}$, and the ceramic yield was $51 \%$ after pyrolysis. $150-200 \mathrm{~nm}$ in thickness of coating film was obtained by spin coating method. The precursor was easily oxidized during process because it was unstable in air. However the oxygen content was limited to 0.5-0.7 to silicon in heat treatment step. Even though the content of nitrogen was decreased by pyrolysis, $\mathrm{Al}-\mathrm{N}$ and $\mathrm{Si}-\mathrm{N}$ bonds were formed in ammonia atmosphere, and $\mathrm{Si}(\mathrm{Al}) \mathrm{ON}$ film was formed with 0.2 in content to silicon.
\end{abstract}

Key words : SiAlON, Energy efficiency, Preceramic polymer, Ceramic precursor

\section{Introduction}

W hile SiAlON materials have been used as a cutting tool material due to their chemical stability, high-temperature stability and excellent mechanical properties, ${ }^{1-3)}$ it has been studied also as an LED material with doping of various metal ions, ${ }^{4-5)}$ and possibilities as a composite material have been consistently proposed. ${ }^{6-8)}$ As SiAlON materials can be produced from clay minerals by carbothermal reduction method, and also by using sol-gel or preceramic polymers ${ }^{9-11)}$ conditions of these precursors such as liquidity, ceramic yield, etc. should be satisfied to be used as a matrix material for composites. Preceramic polymers represented by polycarbosilane, polysilazane, etc. have been developed as a ceramic precursor based on the fact that ceramic production in a variety of forms such as fiber, coating, etc. is possible, and development of various types of preceramic polymers is in demand as studies on ceramic-ceramic composites with functionality are being conducted recently, and studies on ceramic precursors have also been implemented in the case of SiAlON.

Preceramic polymers exhibit pyrolysis behavior at stages before being converted to ceramic. Although most organic molecular structures are decomposed and lost in the pyrolysis process completed around $600^{\circ} \mathrm{C}$, contents of the elements remaining at this time not only become an important factor which determines conditions for additional pyrolysis or crystallization at temperatures above $1000^{\circ} \mathrm{C}$, but also

${ }^{\dagger}$ Corresponding author: Younghee Kim

E-mail : yhkokim@kicet.re.kr

Tel : +82-55-792-2621 Fax : +82-55-792-2758 can affect material properties of the final product. In the existing studies, poly (phenyl carbosilane) (PPCS) as a carbosilane-based polymer has been synthesized, and features of the films formed through a pyrolysis process have been affirmed. ${ }^{12-14)}$ In the present study, $\mathrm{Si}(\mathrm{Al}) \mathrm{ON}$ polymer precursors with addition of a small amount of aluminum(Al) by using imine-based organoaluminum and liquid-phase PPCS as starting materials were prepared, and compositional changes were ascertained in Si-Al-O-N formed from the precursors as a function of pyrolysis conditions.

\section{Experimental Procedure}

\subsection{Synthesis of $\mathrm{Si}(\mathrm{Al}) \mathrm{ON}$ polymer precursors}

$20 \mathrm{ml}$ of DIBAL-H (diisobutylaluminum hydride, reagent grade, Sigma Aldrich) was mixed with $40 \mathrm{ml}$ of anhydrous toluene (99.8\%, Sigma Aldrich) for preparation. After adding $40 \mathrm{ml}$ of anhydrous toluene and $12 \mathrm{ml}$ of ACN (acetonitrile, anhydrous, 99.8\%, Sigma Aldrich) to a 3-neck flask, the solution was agitated in an ice bath. The DIBAL-H solution was prepared in a dropping funnel, and slowly dropped into the ACN solution being agitated. When mixing of ACN and DIBAL-H was completed, it was subjected to heating reaction while maintaining stirring after installing a reflux condenser. At this time, reaction conditions were implemented at $150^{\circ} \mathrm{C}$ and $200^{\circ} \mathrm{C}$ for $6 \mathrm{~h}$ and $3 \mathrm{~h}$, respectively, with the nitrogen atmosphere being maintained in all stages described earlier. The solvent was removed through distillation after the reaction completed.

$1,5,8 \mathrm{~g}$ of AlN polymer precursor were mixed with $20 \mathrm{~g}$ of PPCS (poly(phenyl carbosilane), $M \mathrm{w}$ 1,660, ToBeM Tech) in the liquid condition, respectively, followed by heating reac- 
tion at $250^{\circ} \mathrm{C}$ for 5 days under nitrogen atmosphere. The precursor with the reaction completed was obtained as a brown-colored material of high viscosity.

\subsection{Coating and analysis method}

$20 \mathrm{wt} \%$ solution of $\mathrm{Si}(\mathrm{Al}) \mathrm{ON}$ precursor was prepared. Quartz plate of $15 \times 15 \mathrm{~mm}$ in size was used as a substrate material, spin-coated at the velocity of $3500 \mathrm{rpm}$, and dried subsequently at room temperature. Dried coating film was cured for 1 hour in an oven preheated to $200^{\circ} \mathrm{C}$ to prevent collapse in heat treatment stages, and the heat treatment was performed at $600^{\circ} \mathrm{C}$ under the atmosphere of air, nitrogen and ammonia, respectively.

To check for synthesis status of $\mathrm{Si}(\mathrm{Al}) \mathrm{ON}$ precursors and a change in chemical structures of coating film, FT-IR (JASCO FTIR 4100, Jasco Inc.) analysis was conducted. In the case of precursors, measurements were made in transmission mode by using $\mathrm{KBr}$ window, while ATR(attenuated total reflectance) mode was used in the case of coating film. Pyrolysis behavior of $\mathrm{Si}(\mathrm{Al}) \mathrm{ON}$ was checked by TG-DSC (TGA 400, Perkin Elmer), and element contents were converted from analysis results of X-ray photoelectron spectroscopy (PHI 5000 VersaProbe instrument, Ulvac-PHI Inc.) for dried precursors and coating films obtained by heat treatment.

\section{Results and Discussion}

\subsection{Synthesis of $\mathrm{Si}(\mathrm{Al}) \mathrm{ON}$ precursors}

AlN precursor can be obtained by reacting DIBAL-H with ACN (reaction formula 1), ${ }^{15)}$ the basic structure of which is the same as A. Depending on reaction conditions, A can grow in diversified forms. ${ }^{16-17)}$ Whereas DIBAL-H can be explosively oxidized, AlN precursor has advantages that not only oxidation rates are lowered with formation of polymer body but also it can be formed in a fiber or film form. In the present study, AlN precursor was used as a starting material to produce $\mathrm{Si}(\mathrm{Al}) \mathrm{ON}$ precursor. Here, formation status of C-Al-N bonds was checked by using FT-IR. In general, while the bonds of Al-C and Al-N appear at $630-690 \mathrm{~cm}^{-1}$ and $490-520 \mathrm{~cm}^{-1}{ }^{18)}$ these peaks could be affirmed at the positions of $677 \mathrm{~cm}^{-1}$ and $501 \mathrm{~cm}^{-1}$ in Fig. 1(a).

The structure of PPCS as another starting material is the same as B. The structure and features of PPCS have been elucidated in the existing study. ${ }^{12)}$ In the present study, types of the bonds affirmed in FT-IR are denoted in Fig. 1(b), and schematically shown together in Fig. 1 to ascertain the changes occurring as a function of added amounts of AlN precursor. The FT-IR spectra of $\mathrm{Si}(\mathrm{Al}) \mathrm{ON}$ precursor shown in Fig. 2(c), (d), (e) did not reveal a marked difference when compared with PPCS. However, reduction in intensity of the peak at $2120 \mathrm{~cm}^{-1}$ with an increase in the contents of AlN precursor may be affirmed, which is relevant to Si-H of PPCS and is presumed result from relative reduction in the amount of $\mathrm{Si}-\mathrm{H}$ with new bonds being formed between $\mathrm{Si}$ and $\mathrm{N}$. As Si-N bonds also increase the

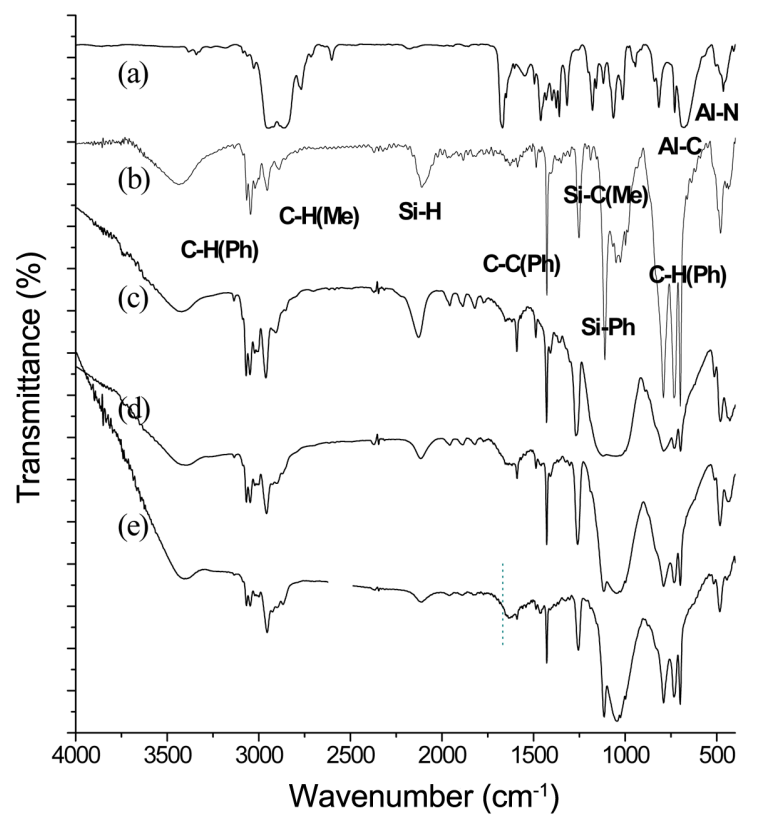

Fig. 1. FT-IR spectra of (a) AlN precursor, (b) poly(phenyl carbosilane), and SiAlON precursor which were prepared with (c) $1 \mathrm{wt} \%$, (b) $5 \mathrm{wt} \%$, and (e) $8 \mathrm{wt} \%$ addition of AlN precursor.

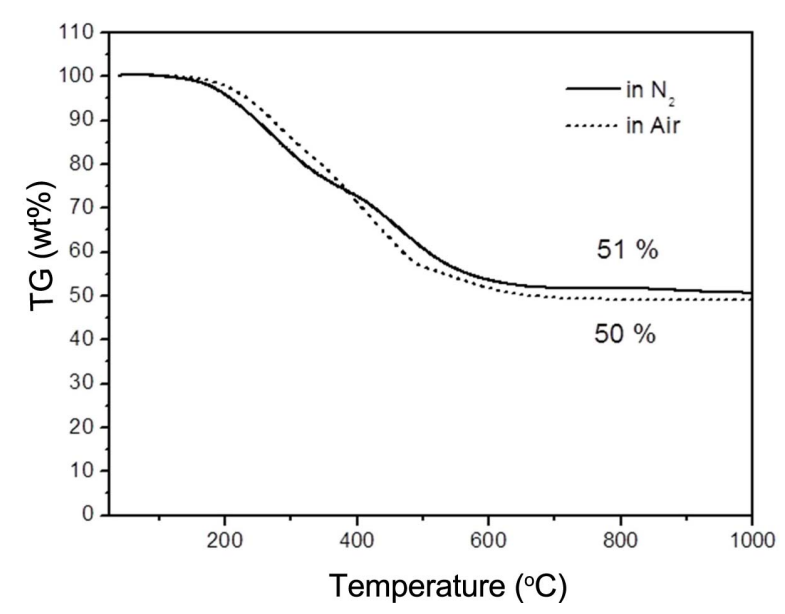

Fig. 2. Thermal gravimetric analysis results of SiAlON precursor.

molecular weight of PPCS, it is presumed that there is an effect according to the added amounts, considering that FTIR spectrum appears broader, the higher the added amount of AlN precursor.

Thermal analysis was conducted for thus-synthesized SiAlON precursor, with the results shown schematically in Fig. 2. Considering pyrolysis behavior in air and nitrogen, stability is shown to be relatively maintained up to $200^{\circ} \mathrm{C}$ without changes in the weight, while pyrolysis is affirmed to be completed above $600^{\circ} \mathrm{C}$ after undergoing weight reduction for a few times at temperatures higher than that. At this time, ceramic yield was shown to be about $50 \%$. 


\subsection{Formation of $\mathrm{Si}(\mathrm{Al}) \mathrm{ON}$ film}

To form a $\mathrm{Si}(\mathrm{Al}) \mathrm{ON}$ film on quartz surfaces, $20 \%$ solution was used, and spin coating was applied. Cross section image of dried film is shown in Fig. 3(a), where the thickness of about $300 \mathrm{~nm}$ was formed. As conditions were air, nitrogen and ammonia, colorless transparent films were obtained in all specimens after heat treatment as shown in Fig. 4. While brown color is exhibited after pyrolysis by an excessive amount of residual carbon in the case of PPCS, a phenomenon very different from this was observed. A cross section of the sample with completion of pyrolysis is schematically shown in Fig. 3(b), where not only no defects occurred in interfaces and cross sections of the film after heat treatment but also dense conditions were maintained, with the thickness of coating layer measured to be 150 - $200 \mathrm{~nm}$. Therefore, a pyrolysis yield at $51 \%$ is affirmed to appear as a shrinkage rate of $30-50 \%$ in the case of a coating film.

\subsection{Evaluation of Si(Al)ON film as a function of heat treatment atmosphere conditions}

Although all thicknesses as well as surface conditions of

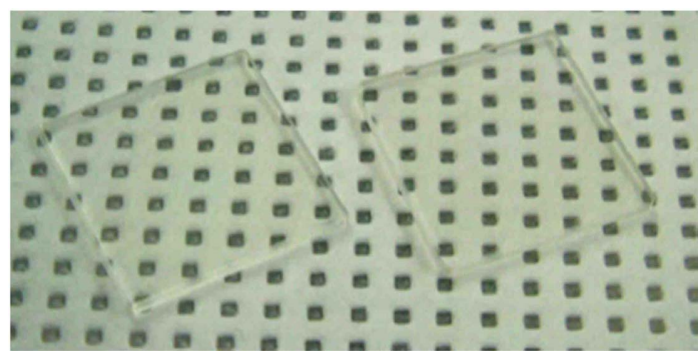

Fig. 3. SiAlON film which was prepared on quartz substrate by spin coating method.

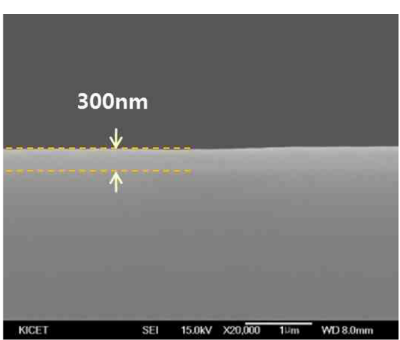

(a)

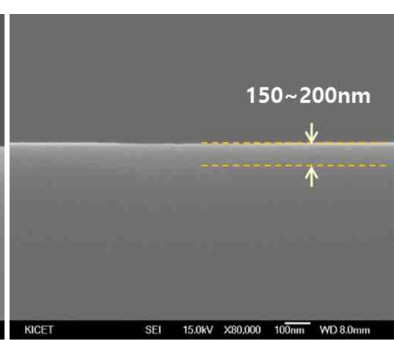

(b)
Fig. 4. Cross-section of (a) the dried film after spin coating, and (b) the film which was prepared at $600^{\circ} \mathrm{C}$ under nitrogen. the coating films formed under different heat treatment atmospheres were constant, all chemical compositions of these films were shown to vary with the atmospheres. Thus, to affirm changes as a function of heat treatment conditions, FT-IR analysis results for coating films are schematically shown in Fig. 5. In the case of $\mathrm{Si}(\mathrm{Al}) \mathrm{ON}$ precursor, large peaks were observed at $3600 \mathrm{~cm}^{-1}, 2960 \mathrm{~cm}^{-1}, 1430 \mathrm{~cm}^{-1}$, $1260 \mathrm{~cm}^{-1}$ positions (Fig. 1(c), (d), (e)), all of which were due to the alkyl structure such as phenyl or methyl. After heat treatment, however, peaks were not affirmed at these positions, which were attributed to the progress of pyrolysis between $200-600^{\circ} \mathrm{C}$ as ascertained in thermal analysis results. In addition, the peak at $1100-1200 \mathrm{~cm}^{-1}$ position was due to Si-O, and it could be affirmed that oxygen flown in was forming bonds with $\mathrm{Si}$ accounting for a relatively large amount upon inflow of the oxygen. Not only that, the peak appearing at $1670 \mathrm{~cm}^{-1}$ position was due to $\mathrm{C}=\mathrm{C}$, and an excessive amount of carbon originating from the phenyl structure was observed to remain while maintaining $\mathrm{C}=\mathrm{C}$ bonds.

To check for the element contents of a coating film, surface analysis was conducted by using X-ray photoelectron spectroscopy (XPS). First, the analysis results for $\mathrm{Al}, \mathrm{O}, \mathrm{C}, \mathrm{N}$ contents converted on the basis of silicon content of 1 are shown in Table 1. Although particular differences were not apparent according to FT-IR analysis results while differences in contents were exhibited per condition, large differences were noted in the contents of carbon and oxygen when the films with completion of drying stage were compared

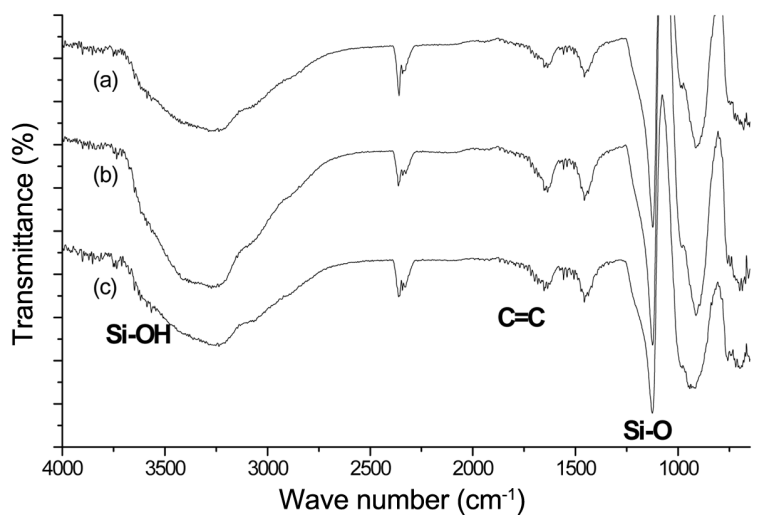

Fig. 5. FT-IR spectra of SiAlON films which were obtained at $600^{\circ} \mathrm{C}$ in (a) air, (b) nitrogen, and (c) ammonia condition.

Table 1. Estimated Formula of SiAlON Film after Heat Treatment at $600^{\circ} \mathrm{C}$ under Various Atmosphere Condition

\begin{tabular}{ccccccccc}
\hline \multirow{2}{*}{ Sample name } & $\begin{array}{c}\text { Heat treatment } \\
\text { condition }\end{array}$ & \multicolumn{4}{c}{ Atomic contents (\%) } & \multirow{2}{*}{ Estimated Formula } \\
\cline { 3 - 6 } & Dried* & 11.00 & 3.95 & 63.62 & 20.12 & 1.30 & $\mathrm{Al} \mathrm{Si}_{0.36} \mathrm{C}_{5.78} \mathrm{O}_{1.83} \mathrm{~N}_{0.12}$ \\
DR & Air & 19.88 & 6.12 & 14.73 & 58.03 & 1.24 & $\mathrm{Al} \mathrm{Si}_{0.31} \mathrm{C}_{2.92} \mathrm{O}_{0.74} \mathrm{~N}_{0.06}$ \\
TH-A & Nitrogen & 21.13 & 6.10 & 11.64 & 60.10 & 1.03 & $\mathrm{Al} \mathrm{Si}_{0.29} \mathrm{C}_{2.84} \mathrm{O}_{0.55} \mathrm{~N}_{0.05}$ \\
TH-N & Ammonia & 20.13 & 7.13 & 12.55 & 55.66 & 4.53 & $\mathrm{Al} \mathrm{Si}_{0.35} \mathrm{C}_{2.77} \mathrm{O}_{0.62} \mathrm{~N}_{0.22}$ \\
\hline
\end{tabular}

*Dried sample after spin coating 
with the films obtained after heat treatment. Since no pyrolysis occurred in the case of dry films (DR) was measured to be 5.78 close to 6 . However, the high contents of $\mathrm{O}$ even as compared with those of the films obtained by heat treatment in atmosphere (TH-A) were unexpected results, which was presumed to be attributable to instability of AlN precursor. In general, organic metal substances are often easily oxidized in atmosphere, and so is the case with $\mathrm{Al}-\mathrm{N}$ bonds. AlN precursor was obtained as brown lumps, and yellow fine powders were observed on the surface as the brown precursor was slowly oxidized when left alone in air. The $\mathrm{Si}(\mathrm{Al}) \mathrm{ON}$ precursor where the reaction was proceeded by mixing of AlN precursor with PPCS was not free from the characteristics of being oxidized in atmosphere either so that relative $\mathrm{O}$ contents are presumed to have been increased with an elapse of time after drying.

On the other hand, in the case of films obtained from heat treatment, oxygen contents were shown to be lower in comparison with those of $\mathrm{DR}$, which is presumed to have been lost by decomposition of incorporated oxygen into NO condigas in pyrolysis process although it could also be due to a short time required for the heat treatment stage after drying. While oxygen contents were maintained at a level of 0.5 0.7 in comparison with silicon, $\mathrm{Al}, \mathrm{O}, \mathrm{C}$ contents as a function of heat treatment conditions showed no large differences among the heat treatment conditions of air-nitrogenammonia. However, in the case of $\mathrm{N}$ contents, they were measured to be the highest for ammonia condition. This seems attributable to the fact that ammonia was also pyrolyzed to react with $\mathrm{Si}$ or $\mathrm{Al}$ simultaneously with occurrence of loss of nitrogen in the heat treatment process. To check for this in more detail, XPS spectrum was affirmed.

Figure 6(a) shows spectrum of $\mathrm{Al} 2 \mathrm{p}$ area, where a peak was shifted to $\mathrm{Al}-\mathrm{O}$ of $75 \mathrm{eV}$ position while heat treatment was implemented, although it appeared at $73.9 \mathrm{eV}$ in the case of DR. ${ }^{19)}$ This is because aluminum and nitrogen elements in the precursor were rearranged while organic structures were decomposed in the heat treatment process, although they had formed bonds with carbon originated in the organic structures. However, in view that the peak appeared in a range of $73-76.5 \mathrm{eV}$ in the case of TH-Am with heat treatment in ammonia, some appeared to maintain Al-N bonds as well while forming Al-O. Also, in the case of $\mathrm{N} 1 \mathrm{~s}$ domain, all of these positions were shifted during heat treatment whereas the peaks for DR were observed in the domain of $398-402 \mathrm{eV}$. In the case of TH-Am, the peaks appeared markedly at the positions of $398 \mathrm{eV}$ and $401 \mathrm{eV}$ unlike for other conditions. This is presumed to be due to formation of $\mathrm{Al}-\mathrm{N}$ or $\mathrm{Si}-\mathrm{N}$ bonds as ammonia gas was decomposed to react with $\mathrm{Al}$ and $\mathrm{Si}$ in the heat treatment process. ${ }^{20)}$

\section{Conclusions}

$\mathrm{Si}(\mathrm{Al}) \mathrm{ON}$ precursor has been synthesized with AlN precursor and PPCS as the starting materials. The precursor was prepared while forming $\mathrm{Si}-\mathrm{N}$ bond, and it showed a

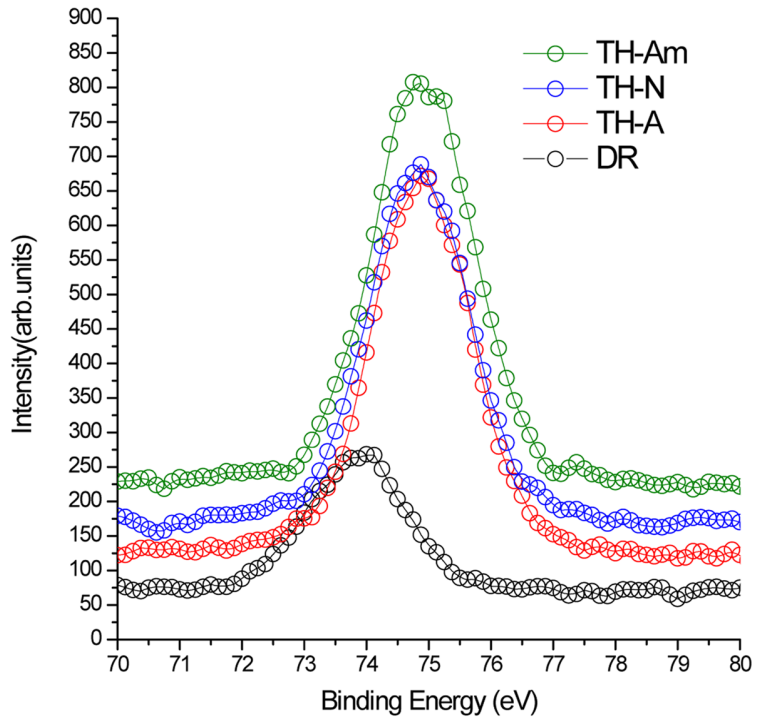

(a)

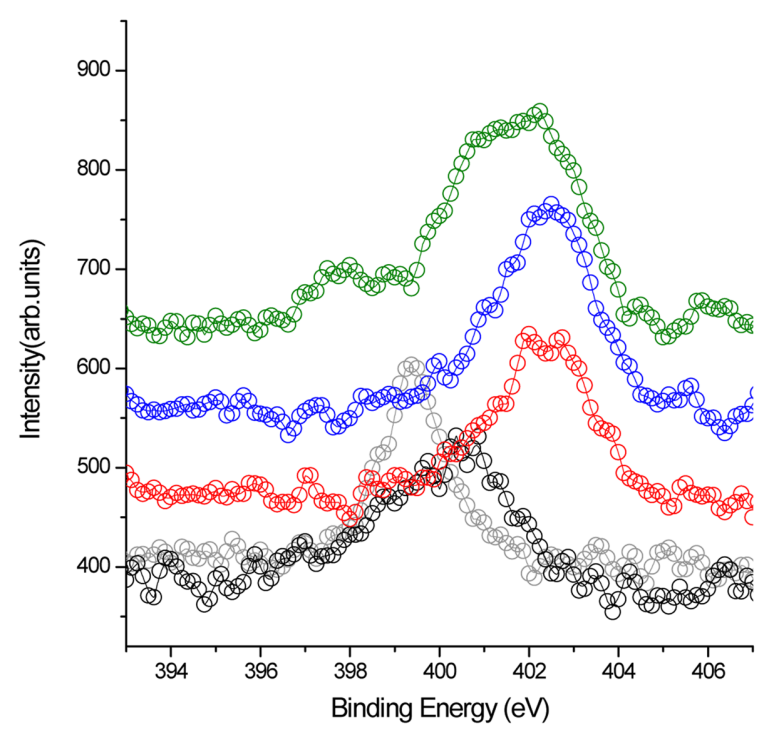

(b)

Fig. 6. (a) $\mathrm{Al} 2 \mathrm{p}$ and (b) $\mathrm{N} 1 \mathrm{~s}$ XPS scan of SiAlON films which was derived from the precursors.

ceramic yield of $51 \%$ through pyrolysis in the range of 200 $600^{\circ} \mathrm{C}$. In addition, coating films of about $150-200 \mathrm{~nm}$ in thickness having a dense structure and an excellent adhesion to the substrate could be obtained by spin-coating method. Although the phenomenon of oxidation occurring with an elapse of time was observed due to vulnerability in oxidation stability in the case of $\mathrm{Si}(\mathrm{Al}) \mathrm{ON}$ precursor prepared in the present study, films with low oxygen contents could be obtained by heat treatment. While the contents of nitrogen were also lowered in the pyrolysis processes, $\mathrm{Si}(\mathrm{Al}) \mathrm{ON}$ films containing an excessive amount of carbon were formed by newly forming Al-N and Si-N bonds simultaneously with pyrolysis under an ammonia atmosphere. 


\section{REFERENCES}

1. Y. G. Gogotsi, "Review: Particulate Silicon Nitride-Based Composites," J. Mater. Sci., 29 2541-56 (1994).

2. M. I. Jones, K. Hirao, H. Hyuga, Y. Yamauchi, and S. Kanzaki, "Wear Properties of Y- $\alpha / B$ Composite SiAlON Ceramics," J. Eur. Ceram. Soc., 23 1743-50 (2003).

3. B. Bitterlich, S. Bitsch, and K. Friederich, "SiAlON Based Ceramic Cutting Tools," J. Europ. Ceram. Soc., 28 [5] 98994 (2008).

4. T. Sekiguchi, Y. Yamamoto, T. Suehiro, and M. Mitomo, "Characterization and Properties of Green-Emitted B-SiA1ON: $\mathrm{Eu}^{2+}$ Powderphosphors for White Light-emitting Diodes," Appl. Phys. Lett., 86211905 (2005).

5. Y. -J Park, S. -H. Lee, W. -K Jung, C. -B. Yoon, and C. -S. Yoon, "The High Density Sintering of Green-Emitting BSiAlON:Eu Ceramic Plate Phosphor," J. Korean Ceram. Soc., 47 [6] 503-08 (2010).

6. R. M. Rocha, J. C. Bressiani, and A. H. A. Bressiani, "Ceramic Substrates of B-SiC/SiAlON Composite from Preceramic Polymers and Al-Si Fillers," Ceram. Int., 40 [9] 13929-36 (2014).

7. Y. Akimune, N. Hirosaki, and T. Ogasawara, "Mechanical Properties of SiC-Particle/sialon Composites," J. Mater. Sci. Lett., 10 [4] 223-26(1991).

8. K. J. MacKenzie, J. Temuujin, M. E. Smith, K. Okada, and Y. Kameshima, "Mechanochemical Processing of Sialon Compositions," J. Eur. Ceram. Soc., 23 [7] 1069-82 (2003).

9. M. Sopicka-Lizer, M. Tańcula, T. Włodek, K. Rodak, M. Marco Hüllerb, V. Kochnevc, E. Fokinad, and K. MacKenziee, "The Effect of Mechanical Activation on the Properties of B-sialon Precursors," J. Eur. Ceram. Soc., 28 [1] 279-88 (2008).

10. O. Yamamoto, M. Ishida, Y. Saitoh, T. Sasamoto, and S. Shimada, "Influence of $\mathrm{Mg}^{2+}$ on the Formation of B-SiAlON by the Carbothermal Reduction-Nitridation of Homogeneous
Gel," Inter. J. Inorg. Mater., 3 [7] 715-19 (2001).

11. E. Bernardo, L. Fiocco, G. Parcianello, E. Storti, and P. Colombo, "Advanced Ceramics from Preceramic Polymers Modified at the Nano-Scale: a Review," Materials, 7 [3] 1927-56 (2014).

12. Y. J. Lee, J. H. Lee, S. R. Kim, W. T. Kwon, H. Oh, J. P. Klepeis, S. J. Teat, and Y. H. Kim, "Synthesis and Characterization of Novel Preceramic Polymer for SiC," J. Mater. Sci., 45 1025-31 (2010).

13. J. J. Kim, J. H. Lee, Y. J. Lee, W. T. Kwon, S. R. Kim, D. J. Choi, H. Kim, and Y. Kim, "Preparation and Characterization of Low k Thin Film Using a Preceramic Polymer," J. Korean Ceram. Soc., 48 [6] 499-503 (2011).

14. J. I. Kim, Y. J. Lee, S. -R. Kim, Y. -H. Kim, J. I. Kim, C. H. Woo, and D. J. Choi, "SiOC Coating on Stainless Steel Using Polyphenylcarbosilane and its Anti-Corrosion Properties," Kor. J. Mater. Res., 21 [1] 8-14 (2011).

15. J. A. Jensen, "Polymer Precursors for Aluminum Nitride," US Patent 5,276,105 1994.

16. Y. Mori and Y. Sugahara, "Pyrolytic Organic-to-Inorganic Conversion of Precursors into AlN- A Review," J. Ceram. Soc. Japan, 114 [6] 461-72 (2006).

17. M. Veith, "Cage Compounds with Main-Group Metals," Chem. Rev., 90 3-16 (1990).

18. D. C. Bradley, I. S. Harding, I. A. Maia, and M. Motevalli, "Synthesis and Crystal Structure of Dimeric Dialkylaluminump-dialkylamido Compounds," J. Chem. Soc., Dalton Trans., 2969-79 (1997).

19. W. Qian, H. Lai, X. Pei, J. Jiang, Q. Wu, Y. Zhang, X. Wang, and Z. Hu, "Improving Field Emission by Constructing CsI-AlN Hybrid Nanostructures," J. Mater, Chem., 22 18578-82 (2012).

20. S. M. Castanho and R. Moreno, "Characterization of $\mathrm{Si}_{3} \mathrm{~N}_{4}$ Powder in Aqueous Dispersions," Cerâmica, 44 [287-288] (1998) DOI http://dx.doi.org/10.1590/S0366-69131998000400006. 